\title{
Spatio-Temporal Analysis of Vegetation Dynamics as a Response to Climate Variability and Drought Patterns in the Semiarid Region, Eritrea
}

\author{
Simon Measho ${ }^{1,2,3}$, Baozhang Chen ${ }^{1,2,4, *}$, Yongyut Trisurat ${ }^{5}$, Petri Pellikka ${ }^{6,7}{ }^{\mathbb{C}}$, Lifeng Guo ${ }^{1,2}$, \\ Sunsanee Arunyawat ${ }^{8}{ }^{(0)}$, Venus Tuankrua ${ }^{9}$, Woldeselassie Ogbazghi ${ }^{10}$ and Tecle Yemane ${ }^{11}$ \\ 1 State Key Laboratory of Resources and Environment Information System, Institute of Geographic Sciences \\ and Natural Resources Research, Chinese Academy of Sciences, 11A, Datun Road, Chaoyang District, \\ Beijing 100101, China; simon@igsnrr.ac.cn (S.M.); lifeng.guo.15b@igsnrr.ac.cn (L.G.) \\ 2 University of Chinese Academy of Sciences, No. 19A, Yuquan Road, Beijing 100049, China \\ 3 Hamelamalo Agricultural College, National Commission for Higher Education, Keren 397, Eritrea \\ 4 Jiangsu Center for Collaborative Innovation in Geographical Information Resource Development and \\ Application, Nanjing 210023, China \\ 5 Faculty of Forestry, Kasetsart University, Bangkok 10900, Thailand; fforyyt@ku.ac.th \\ 6 College of Global Change and Earth System Science, Beijing Normal University, Beijing 1000875, China; \\ petri.pellikka@helsinki.fi \\ 7 Earth Change Observation Laboratory, Department of Geosciences and Geography, University of Helsinki, \\ FI-00014 Helsinki, Finland \\ 8 Office of Land Use Planning and Policy, Land Development Department, Ministry of Agriculture and \\ Cooperatives, Bangkok 10900, Thailand; anyaey@gmail.com \\ 9 Department of Conservation, Faculty of Forestry, Kasetsart University, 50 Ngamwongwan Road, Chatuchak, \\ Bangkok 10900, Thailand; ffor.venus@gmail.com \\ 10 Department of Land Resource and Environment, Hamelmalo Agricultural College, Keren 397, Eritrea; \\ wogbazghi@gmail.com \\ 11 Water Resource Department, Ministry of Land, Water and Environment, Asmara 25387, Eritrea; \\ tecley@yahoo.com \\ * Correspondence: baozhang.chen@igsnrr.ac.cn; Tel.: +86-010-64889574
}

Received: 20 February 2019; Accepted: 19 March 2019; Published: 26 March 2019

\begin{abstract}
There is a growing concern over change in vegetation dynamics and drought patterns with the increasing climate variability and warming trends in Africa, particularly in the semiarid regions of East Africa. Here, several geospatial techniques and datasets were used to analyze the spatio-temporal vegetation dynamics in response to climate (precipitation and temperature) and drought in Eritrea from 2000 to 2017. A pixel-based trend analysis was performed, and a Pearson correlation coefficient was computed between vegetation indices and climate variables. In addition, vegetation condition index (VCI) and standard precipitation index (SPI) classifications were used to assess drought patterns in the country. The results demonstrated that there was a decreasing NDVI (Normalized Difference Vegetation Index) slope at both annual and seasonal time scales. In the study area, $57.1 \%$ of the pixels showed a decreasing annual NDVI trend, while the significance was higher in South-Western Eritrea. In most of the agro-ecological zones, the shrublands and croplands showed decreasing NDVI trends. About $87.16 \%$ of the study area had a positive correlation between growing season NDVI and precipitation $(39.34 \%, p<0.05)$. The Gash Barka region of the country showed the strongest and most significant correlations between NDVI and precipitation values. The specific drought assessments based on VCI and SPI summarized that Eritrea had been exposed to recurrent droughts of moderate to extreme conditions during the last 18 years. Based on the correlation analysis and drought patterns, this study confirms that low precipitation was mainly attributed to the slowly declining vegetation trends and increased drought conditions in the semi-arid region. Therefore,
\end{abstract}


immediate action is needed to minimize the negative impact of climate variability and increasing aridity in vegetation and ecosystem services.

Keywords: vegetation dynamics; climate variability; NDVI; drought; VCI; precipitation; temperature; SPI

\section{Introduction}

Climate is a prime driver of vegetation dynamics and it dictates the distributions of plant species and vegetation [1]. Vegetation change is affected by precipitation and temperature, and recurrent droughts, which can be the impacts of climate change and global warming [2]. With increases in climate variability and a warming trend in Sub-Saharan Africa, and particularly in East Africa, there have been changes towards extreme rainfall events, and an increase in seasonal mean temperature [3]. Such trends can bring about an impact on vegetation change and agricultural production, especially in countries like Eritrea, where the majority of its population depends on rain-fed agriculture. There is a need to develop proper drought monitoring methods in order to mitigate and adapt to climate change impacts. Drought monitoring usually has many aspects, such as hydrological, meteorological, and agricultural aspects, and analyzing vegetation dynamics and climate variables together can lead to a better understanding of interconnected and correlated drought-related parameters [4].

The use of remote sensing and geographic information systems (GIS) technology is increasing globally in the identification of patterns in spatial data and vegetation dynamics based on the time-series of satellite imageries [5,6]. The traditional methods of mapping of large areas mainly based on field surveys are not cost-effective to track vegetation changes, but the geospatial technology provides better means of studying vegetation dynamics [7]. The available remotely- sensed time-series of vegetation indices have been used to analyze the trends of vegetation change and drought assessment [5].

Since the 1980s, many researchers have utilized Normalized Difference Vegetation Index (NDVI) as an indicator of vegetation growth and status, and to identify the spatial density and phenology of vegetation. Moreover, NDVI has been used to explore the relationship between NDVI and climate factors in different geographic areas and ecosystems [8]. One of the most commonly used NDVI datasets for vegetation dynamics analysis and drought monitoring is the Moderate Resolution Imaging Spectro-radiometer (MODIS) products, which can give continuous and relatively high-resolution images as time series $[9,10]$.

Different indices have been developed to quantify drought in relation to vegetation dynamics. MODIS-based Standard Vegetation Index (SVI) has recently been used to support drought monitoring, while Standardized Precipitation Index (SPI) is commonly used to characterize meteorological drought in the range of time scales [11,12]. Vegetation Condition Index (VCI), which can be derived from NDVI or Enhanced Vegetation Index (EVI), is also one of the most utilized indices for drought monitoring [13]. However, in most of the studies using such indices for vegetation dynamics and drought trend studies, they are usually done at global and regional scales, which is not an appropriate scale for decision makers to take proper mitigation measures. The integration of remotely sensed data with climate datasets, e.g., Climate Engine powered with Google Earth, has provided a very valuable spatial dataset to researchers and provided a convenient platform to further reprocess and extract useful spatial information at convenient scales. Indicators such as the SPI and NDVI can generate the best correlation-anticipation relationships for early signs of drought impacts and drought monitoring purposes, such as identifying hot spots at local scales [14,15].

Eritrea is located in the Horn of Africa in the eastern part of the Sahel zone. It is climatologically under the influence of the Sahara Desert and the Arabian Desert. Climate variability in Eritrea is enormous [3], and there is a high rate of vulnerability to the effects of climate change because the 
population depends mainly on rain-fed agriculture [16]. Eritrea has been vulnerable to climate change, especially over the past 60 years, as the temperature has been risen by approximately $1.7^{\circ} \mathrm{C}$. This has had a tremendous impact on biodiversity and the overall loss of resilience of the ecosystem [17]. Moreover, the country is prone to climate variability and recurrent droughts, almost $50 \%$ of the country receive less than $300 \mathrm{~mm}$ of precipitation annually, and the amount varies from year to year [17]. However, there are no studies carried out to investigate how intensively climate variability has affected the terrestrial vegetation and ecosystem services.

Natural vegetation in Eritrea is sparse and is characterized by acacia trees (Acacia ssp.) and bushes. Most of the vegetation types are semi-arid, with either cultivated annual plants or deciduous perennials produced during the short rainy seasons. The country was endowed with a variety of indigenous tree species which had been devastated due to the recent war, land use changes, and recurrent droughts. Deforestation is one of the most serious environmental consequences caused by land use change and climate change, due to prolonged drought periods and erratic rainfall patterns [18]. Different adaptation and intervention measures, such as soil and water conservations, are practiced, but as stated in the report of Ministry of Land, Water and Environment (MoLWE, 2015), mitigation and adaption measures are subject to continuous scrutiny. In addition, research applying time series data is required to quantify the outcomes of the interventions. Agricultural production in Eritrea is low, which can be greatly attributed to the fragile ecosystems with frequent droughts and seasonal temperature increases [19]. The United Nations Office for Disaster Risk Reduction (EM-DAT) stated that drought events covered 50\% of all natural hazards between 1990 and 2014 in Eritrea [20], and is, thus, the main natural hazard. The drought conditions had been exacerbated by war and political conflict as the country had experienced thirty years of prolonged war for independence and two years of border conflict. Population growth and re-settlement programs in forested areas of the Anseba and Gash Barka regions could have increased pressure on land cover changes of the country.

Apart from basic vegetation cover maps of Afri-Cover Project (1999) and land cover maps of Food and Agricultural Organization (2009), the availability of spatial data is limited. Thus, there is a great demand for spatial data, which can provide time-series of vegetative trends and drought vulnerability maps for decision makers to properly manage natural resources, to monitor drought impacts, and to plan sustainable ecosystem functioning. Moreover, there are plant species that are at the verge of extinction because of climate change and invasive exotic plants like prosopsis (Temri mussa). The occurrence of droughts needs to be verified through spatial analysis of historical datasets of vegetation changes and climatic variables.

The overall objective of this research is to identify the causes and the relationships between vegetation dynamics and climate variability, and drought conditions in Eritrea. The specific objectives are: (i) to analyze spatio-temporal trends of vegetation dynamics in the last 18 years based on climate and remote sensing data; (ii) to identify the main causes of vegetation change in relation to climatic factors (temperature and precipitation); and (iii) to assess drought patterns using vegetation condition and standard precipitation indices.

\section{Data and Methods}

\subsection{Study Area}

Eritrea consists of three major terrestrial geographic regions: the central highlands, the eastern lowlands, and western lowlands. The dominant eco-geographical regions of global vegetation classifications are the Sahelian Acacia Savana and Ethiopian Xeric grassland and shrublands (Figure 1a). World Food and Agricultural Organization (FAO) in 1997 identified six agro-ecological zones in Eritrea: Semi-deserts, Arid Lowlands, Moist Lowlands, Moist Highlands, Arid Highlands, and Sub-humid Highlands (Figure 1b). A large part of the country falls under the category of Arid Lowlands and Semi-Desert Zones. 

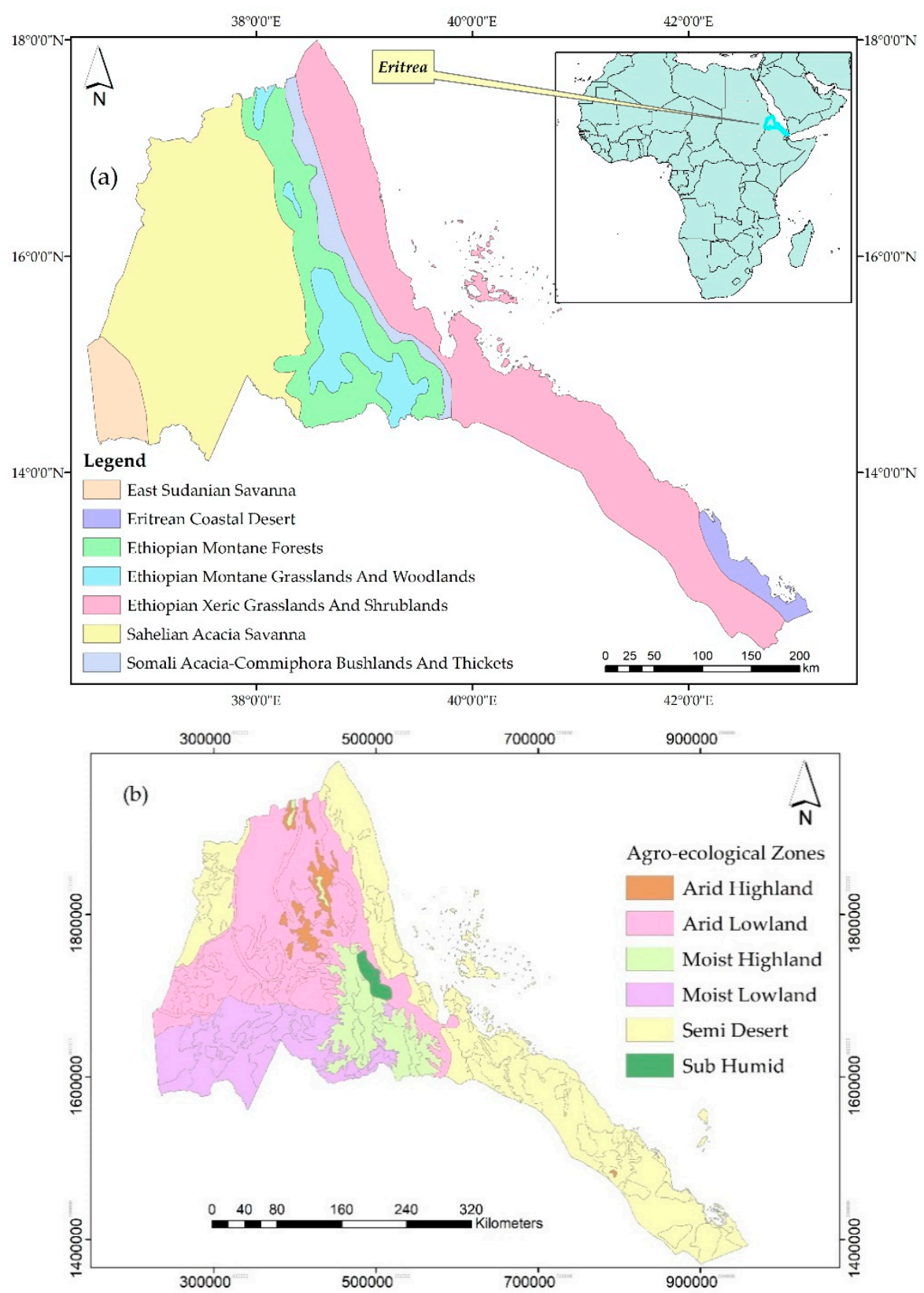

Figure 1. Eritrea and its eco-geographical regions. (a) The Nature Conservancy (2003), and Agro-ecological zones of Eritrea (b) Food and Agricultural Organization (1997).

Figure 2a shows the administrative regions of the country and Figure $2 \mathrm{~b}$ represents the land cover types extracted from the European Space Agency (2016) imagery dataset. The most dominant land cover types are Bare Areas and Cropland, accounting for $38 \%$ and $18 \%$ of the land surface, respectively. The highland plateau of Eritrea descends gently to western lowlands, but quite rapidly to eastern lowlands, and many places are characterized by undulating hills and steep slopes. The central highlands reach up to $3000 \mathrm{~m}$ above sea level, while the Danakil depression found in the Southern Red Sea region is more than $100 \mathrm{~m}$ below sea level, being one of the deepest and hottest places in the world (Figure 3). The topographic variation affects the rainfall and temperature regimes of the country, which in turn influences the spatio-temporal variability of vegetation dynamics. 

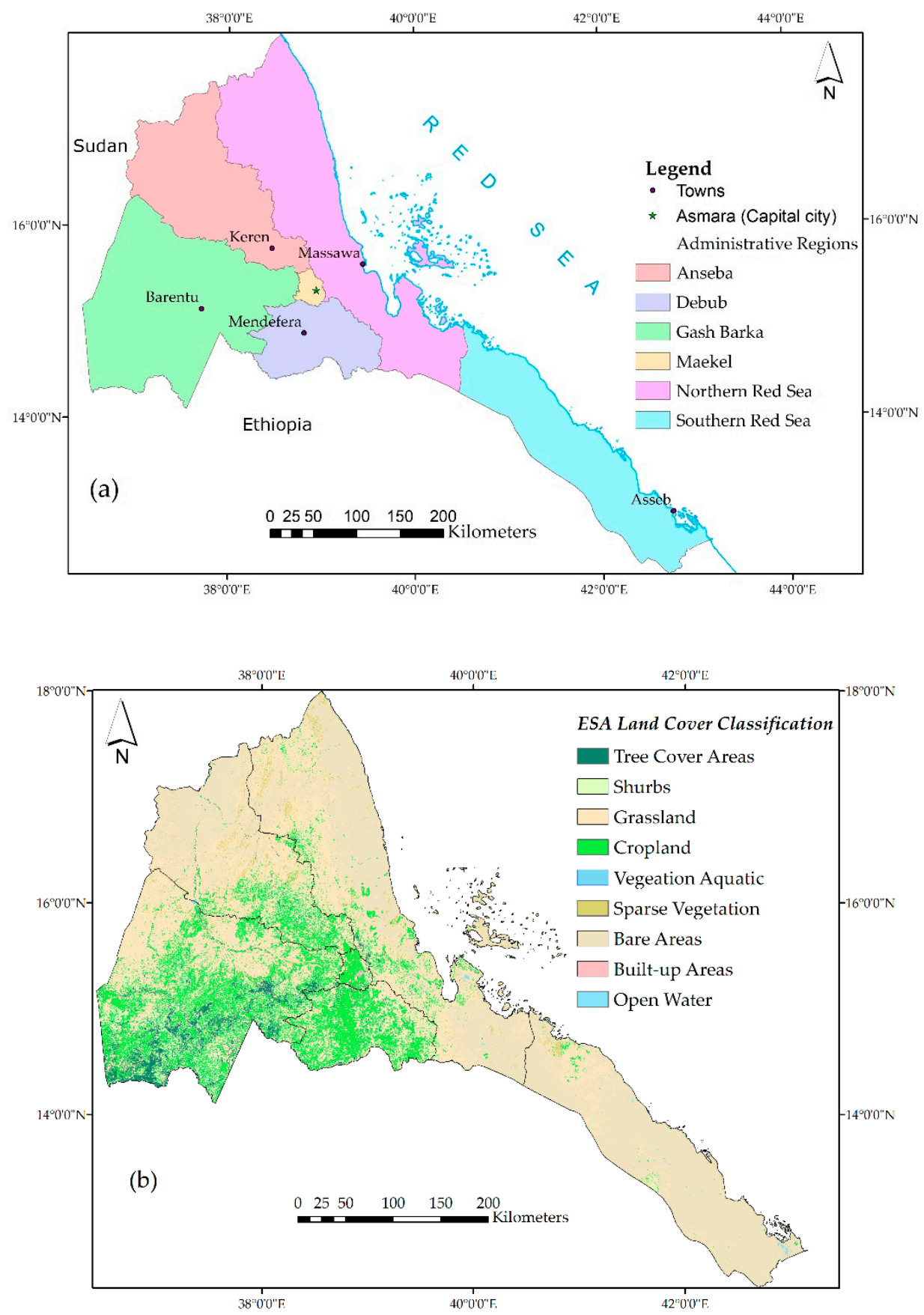

Figure 2. Administrative regions of Eritrea (a), and European Space Agency land cover (2016) map (b).

Eritrea's climate is classified as Hot Semi-Arid Climate (BSh) or Hot Desert Climate (BWh) in Köppen's climate classification. Mean temperature ranges from $18{ }^{\circ} \mathrm{C}$ in the highlands to $35^{\circ} \mathrm{C}$ in the lowlands and is the main factor in defining the Eritrean agro-ecological zones [21]. Rainfall in most parts of Eritrea is low and highly variable, and according to MoLWE report [17], it ranges from $50 \mathrm{~mm}$ along the coastal area to $1000 \mathrm{~mm}$ in the eastern escarpment, while $40 \%$ of the country receives precipitation between $300-600 \mathrm{~mm}$ in 2015 . The rainfall is inadequate to support agricultural production, especially during drought years. Based on the Climate Hazards Group InfraRed Precipitation with Station data of daily satellite extractions (CHIRPS daily), the average annual precipitation between 2000 and 2017 in Eritrea is $334 \mathrm{~mm}$, while almost 50\% of the country receives less than $300 \mathrm{~mm}$. 


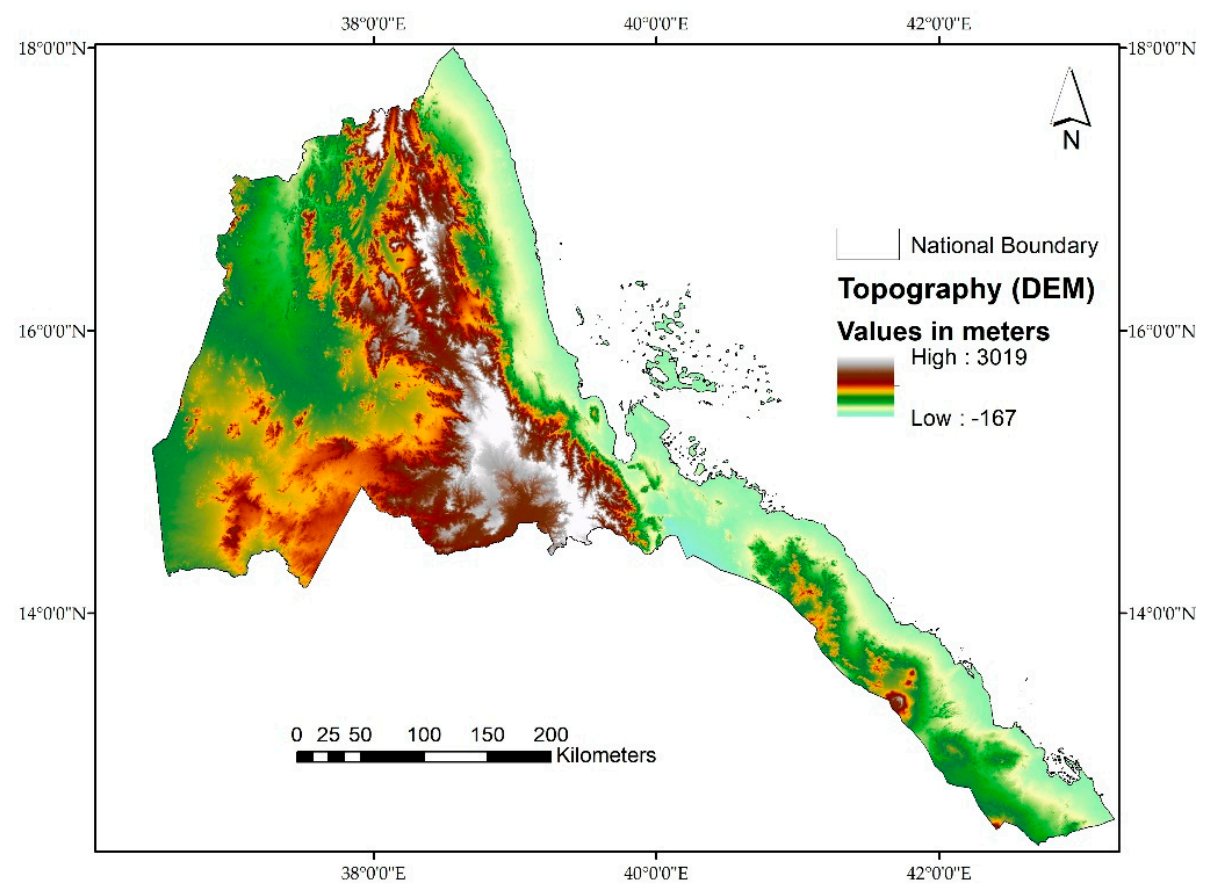

Figure 3. Topographic map of Eritrea (Digital Elevation Modelsource: Shuttle Radar Topography Mission 30-m resolution).

\subsection{Datasets}

An 18-year long time series of NDVI and EVI data at 250-m resolution from Moderate Resolution Imaging Spectro-radiometer (MODIS) Terra 16-day data (LPDAAC NASA products) were exploited in our study. Six products from MODIS13Q1 version were used for quantifying Vegetation Condition Index (VCI) and trend analysis. The products provide detailed measurements of pixel values at 16-day time steps, like the MODIS NDVI, while the EVI is a supplement, as it can detect the reflected light in areas of high biomass and corrects distortions of background scattering, which is applicable in drought-related studies [22]. VCI for the multi-annual growing seasons was also generated from the NDVI dataset to be related to drought monitoring purposes. VCI was calculated in ArcGIS using local cell statistics of the Spatial Analysis tool for each main growing season in a year (please refer to Section 2.3.3 for details).

We applied the Climate Engine data source powered by the Google Earth Engine as the main source of both remote sensing and climate datasets. The data were filtered and spatially processed in easily downloadable file formats, such as GeoTIFF and Comma-separated values, through the web browser (http://climateengine.org/app/). Climate Engine has revolutionized the service of providing processed spatial datasets and eased computational barriers by using Google's parallel cloud computing platform [23].

The datasets used from the Climate Engine include MODIS datasets, SPI, and precipitation datasets of CHIRPS daily at $0.05^{\circ}$ resolution. CHIRPS data were helpful in extracting multi-annual and growing season averages of the total precipitation for the time series trend analysis and drought monitoring purposes. It is recommended to use precipitation datasets, such as CHIRPS, when working with drought assessment and monitoring activities [24].

Multi-annual and seasonal mean temperatures of Climate Forecast System Reanalysis (CFSR) datasets (1/5 and 3/10 degrees) from the National Center for Environmental Prediction were also accessed and re-processed. Moreover, to report and aggregate the results of both MODIS vegetation indices and climatic datasets, land cover datasets at 20-m resolution from the European Space Agency (ESA, 2016) were re-sampled, processed, and used. Shapefiles of administrative units and 
agro-ecological zones of Eritrea were also used to integrate data and to summarize outputs as zonal statistics tables.

\subsection{Methods}

\subsubsection{Linear Regression Model}

A linear regression model was applied to detect trends in vegetation greenness change using the main growing season and annual datasets from Climate Engine from 2000 to 2017. A pixel-based linear regression model (LRM) was applied to analyze the NDVI spatial trend during the study period. The slope was calculated from mean values of NDVI as the dependent variable and the time as an independent variable. In order to analyze MODIS NDVI change through time, a pixel-based smallest power-function linear regression formula, as proposed and used by previous authors, was applied, as given in Equation (1) [25-27]:

$$
\text { Slope }=\frac{n \times \sum_{i=1}^{n} X_{i} Y_{i}-\sum_{i=1}^{n} X_{i} \sum_{i=1}^{n} Y_{i}}{n \times \sum_{i=1}^{n} X_{i}^{2}-\left(\sum_{i=1}^{n} X_{i}\right)^{2}}
$$

where Slope represents the changing trends in MODIS NDVI values, and $n$ is the sample number (18 years). $Y_{i}$ is the value of the dependent variable and $X_{i}$ the time as an independent variable, both representing the $i$ th year.

The slope values close to zero means there was not much variation in vegetation greenness through time, while slope values greater than zero show an increasing vegetation trend over time, and the trend may decrease if the slope values are less than zero. The significance of the trend was tested using F-Test (coeff function) and a p-value of less than 0.05 (95\% confidence level) in MATLAB R2016a software for each pixel. As originally stated by Weatherhead [28] and later used by Eckert et al. and Jiang et al. [26,29], an equivalent NDVI change based on trend values and p-value thresholds was used to re-categorize the pixel values into a significant decrease, not-significant decrease, significant increase, and not-significant increase.

\subsubsection{Pearson Correlation Coefficient}

In order to give a broader picture of the correlation and spatial patterns between vegetation indices and climate factors, a pair-wise Pearson Correlation Coefficient (PCC) was first computed using R software to measure the linear association among the variables, including NDVI, EVI, temperature, and precipitation for both annual and growing season months. PCC plots were generated from the mean values of the vegetation indices and climatic variables to show distributional maps using R-software; the NDVI gave higher output values than EVI in the study area, as such NDVI values were used to calculate the trends and correlations.

To understand in detail the role of climatic factors on vegetation dynamics and to depict spatial relationships through time, a pixel-based PCC analysis between MODIS NDVI and climate variables (Precipitation and Temperature) were computed using the commonly used approach, as shown in Equation (2) [25,30,31]:

$$
r_{x y}=\frac{\sum_{i=1}^{n}\left[\left(x_{i}-X\right)\left(y_{i}-Y\right)\right]}{\sqrt{\sum\left(x_{i}-X\right)^{2} \sum_{i=1}^{n}\left(y_{i}-Y\right)^{2}}}
$$

where $r_{x y}$ is the PCC of $x$ and $y$ variables, $y_{i}$ is the dependent variable representing mean NDVI of the $i$ th year, and $x_{i}$ is the independent variable representing either average total precipitation or mean temperature of the $i$ th year. $Y$ is the average NDVI for the study period (18 years), and $X$ is the total mean precipitation or temperature for the study period.

The values of PCC extend from negative to positive correlation $(-1$ to +1$)$. Time series spatial patterns for the study period were performed and correlation coefficient maps were generated in MATLAB and further processed in ArcGIS software. The PCC was evaluated using F-Test (CORRCOEF 
function) at each pixel and a p-value less than 0.05 was considered statistically significant. The climatic raster datasets were resampled using the bilinear method and reprocessed to match with the 250-m resolution of MODIS Vegetation Indices. Some pixels with extremely low precipitation values were marked as no-data values in extracting the correlation coefficients in both periods, as the areas represent part of the Danakil depression.

\subsubsection{Vegetation Condition Index and Standard Precipitation Index}

VCI is calculated based on inputs like NDVI and EVI, and different authors have used either NDVI or EVI as a base for calculating VCI in Equation (3) [32-35]. VCI is a pixel-based analysis for finding vegetation conditions at a specific location of the pixel by considering the mean of the multi-annual variability and the minimum and maximum variability of the Vegetation Index.

$$
V C I=\frac{\left(N D V I_{i}-N D V I_{\text {min }}\right)}{\left(N D V I_{\text {max }}-N D V I_{\text {min }}\right)} \times 100
$$

where $N D V I_{i}$ represents the mean Vegetation Index values for the main growing season in a certain year, $N D V I_{\text {min }}$ and $N D V I_{\text {max }}$ are the multiple-year minimum and maximum NDVI values calculated for each pixel of the main growing season from 2000 to 2017.

As proposed by many authors [33-35], we applied a threshold of 35\% to classify the VCI. NDVI drought classification of different levels of the growing season from a maximum of $35 \%$ to a minimum of $0 \%$ was extracted for each year of the observation period (Table 1 ).

Table 1. Drought classification levels using Vegetation Condition Index (VCI) extracted from Moderate Resolution Imaging Spectro-radiometer Normalized Difference Vegetation Index (NDVI).

\begin{tabular}{cc}
\hline VCI Percentage & Drought Severity Level \\
\hline$>35$ & No drought \\
20 to 35 & Moderate drought \\
10 to 20 & Severe drought \\
$<10$ & Extreme drought \\
\hline
\end{tabular}

In order to specifically understand the drought conditions and vegetation development, more emphasis was given to the main season of 2017, which was mapped in detail view and in comparison to the average drought conditions of the last 17 years based on MODIS NDVI datasets. Moreover, time series VCI maps of all the years were generated and interpreted to identify areas of drought vulnerability at a pixel level of analysis.

SPI is used to determine meteorological drought, but it can be helpful for finding parallel drought patterns with VCI. It is one of the most commonly used indices for characterizing drought dynamics. We applied similar drought categories for five classes with modification in the lower limit, as in a previous study [36]. An aggregated dataset of SPI is a recommended index by the World Meteorological Organization (WMO) for agricultural drought purposes [37].

SPI merely calculates the standard deviation of the observed value differences from the historical mean, where positive and negative values show deviation from the median precipitation. We aggregated and used four months mean SPI values (SPI-4) from CHIRPS datasets for the same growing season of all years in order to make a pixel-based analysis, along with their spatial extents. The values below zero ranging from mild to extreme drought conditions were compared and classified in the growing season of each year (Table 2). 
Table 2. Drought classification using SPI based on 4 months CHRIPS daily aggregate dataset.

\begin{tabular}{cc}
\hline SPI Range & Drought Severity Level \\
\hline$>0$ & No drought \\
-1 to 0 & Mild drought \\
-1.5 to -1 & Moderate drought \\
-1.5 to -2 & Severe drought \\
$<-2$ & Extreme drought \\
\hline
\end{tabular}

\section{Results}

\subsection{Spatial and Temporal Trends in Vegetation Cover}

NDVI and EVI datasets for both annual and main growing season months of the study period were aggregated to generate spatial distribution maps. Figure 4 shows aggregated pixel-based distribution maps of multi-annual mean NDVI, EVI, temperature, and average total precipitation of the study period (18 years). The mean annual NDVI and EVI from 2000 to 2017 revealed that there were high values in the southwest and in Central Highlands, while the values decreased towards the lowlands in the east and northwestern parts.
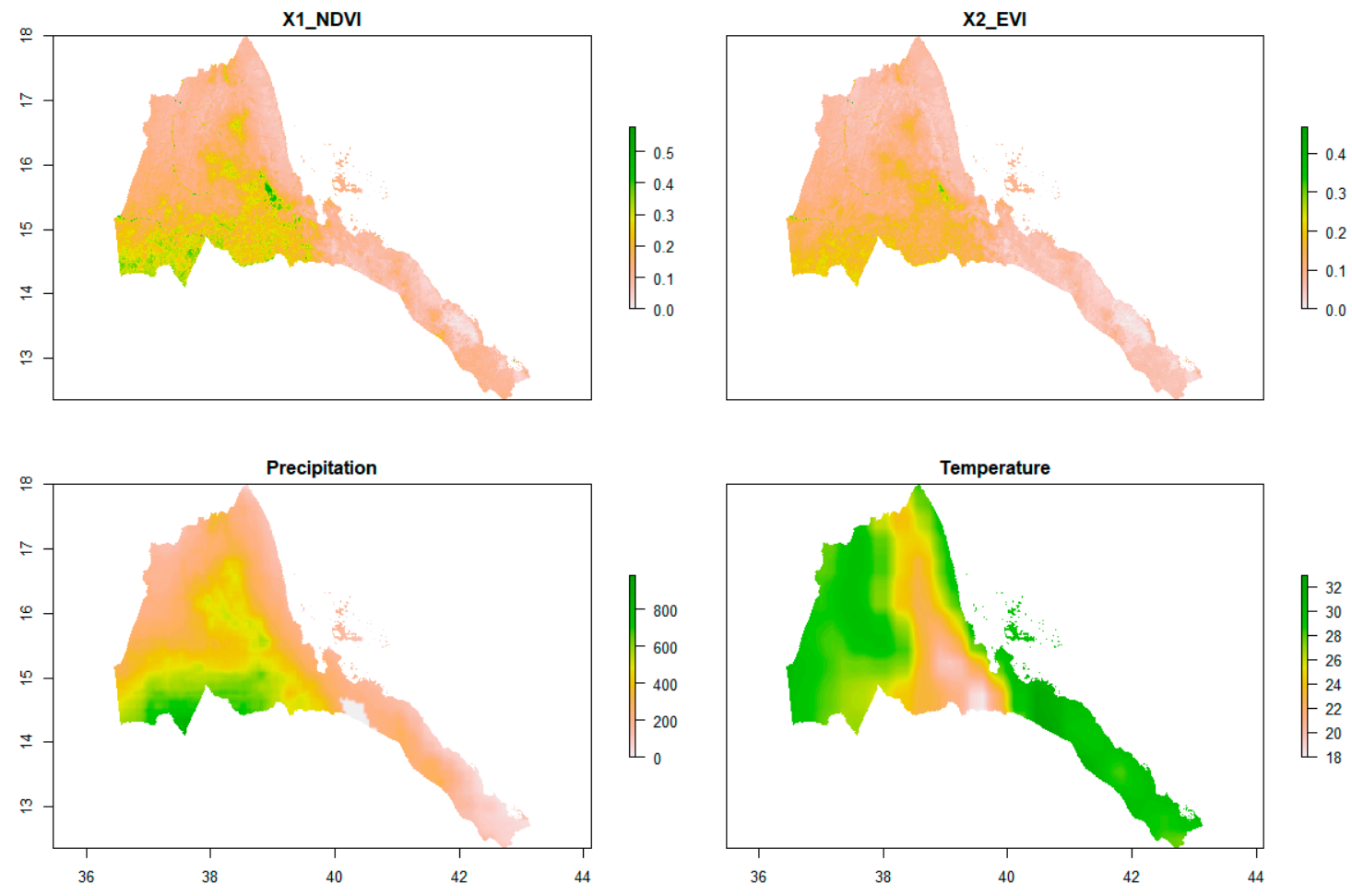

Figure 4. Mean annual NDVI, EVI, temperature, and total precipitation during 2000-2017.

The highest values of vegetation indices (Figure 4) were dominant in the escarpment between the central highland and eastern lowlands. These areas are still rich in forests due to steep slopes and fog deposits similarly as in Saudi Arabian mountains [38]. The lowest values were around the south-west part of the Southern Red Sea region close to Denakil depression areas. Those areas with low NDVI and EVI values reflect low vegetation coverage and aridity. The mean annual values of the vegetation indices were low due to variations in climatic factors and recurrent droughts affecting the distribution and terrestrial plant growth. The multi-annual mean NDVI and EVI for the whole country were 0.158 and 0.1. Mean EVI and NDVI in comparison with the annual values slightly increased during the main growing season with values of 0.184 and 0.12 , respectively. 
A pixel-based NDVI trend analysis was carried out to understand the specific trend and changes in vegetation cover during the study period. Figure 5 shows slope changes of the annual and growing season mean NDVI over 18 years, including the significance of the trends. Even though there were areas of increasing and decreasing NDVI trends, in both maps the overall changing trend per pixel showed more of a decreasing trend over time; thus, the change through the years was substantial. The annual and growing season trend values ranged from -0.02483 to 0.02854 , and -0.03418 to 0.03547 (NDVI per year), respectively. In both periods, the lowest values appeared in the south-western parts of Eritrea, while the highest values were in the north-central parts of the country. In the entire country, $57.15 \%$ of all pixels showed a decreasing trend for the annual mean NDVI with significant decreases in many places. Similarly, $58.74 \%$ of all pixels of the country reflected a decreasing trend for the main growing season.

The annual and growing season mean NDVI trends were overlaid with agro-ecological zones (Figure 1b). Zonal statistics were extracted based on soil type with a detailed spatial sub-unit. All mean NDVI trend values for Moist Highland and Moist Lowland agro-ecological zones turned out to be of decreasing vegetation productivity. Moist Lowland zone followed by Semi-Desert zone showed the highest decrease in NDVI trends for the annual and main growing season periods. The Arid Lowland and Humid zones showed some increases in the trends, especially in the north-central part of the country.

Zonal statistics table extractions [39] based on the administrative regions of Eritrea (Figure 2a) summarized that Gash Barka region followed by Debub region showed the biggest decrease in NDVI trends in both the annual and main growing season. Northern Red Sea and Meakel regions were mainly characterized by a non-significant decrease of NDVI trends in both periods. Anseba Region recorded the highest increase in NDVI trends for the two periods. Integration of the mean annual and growing season NDVI with ESA land cover (Figure 2b) also showed shrubs and croplands showed the greatest decreasing mean NDVI trend values, however sparse vegetation and tree cover areas showed an increasing trend. Shrubs are the most dominant vegetation cover in the Central Highland and Eastern Region of Eritrea [40].

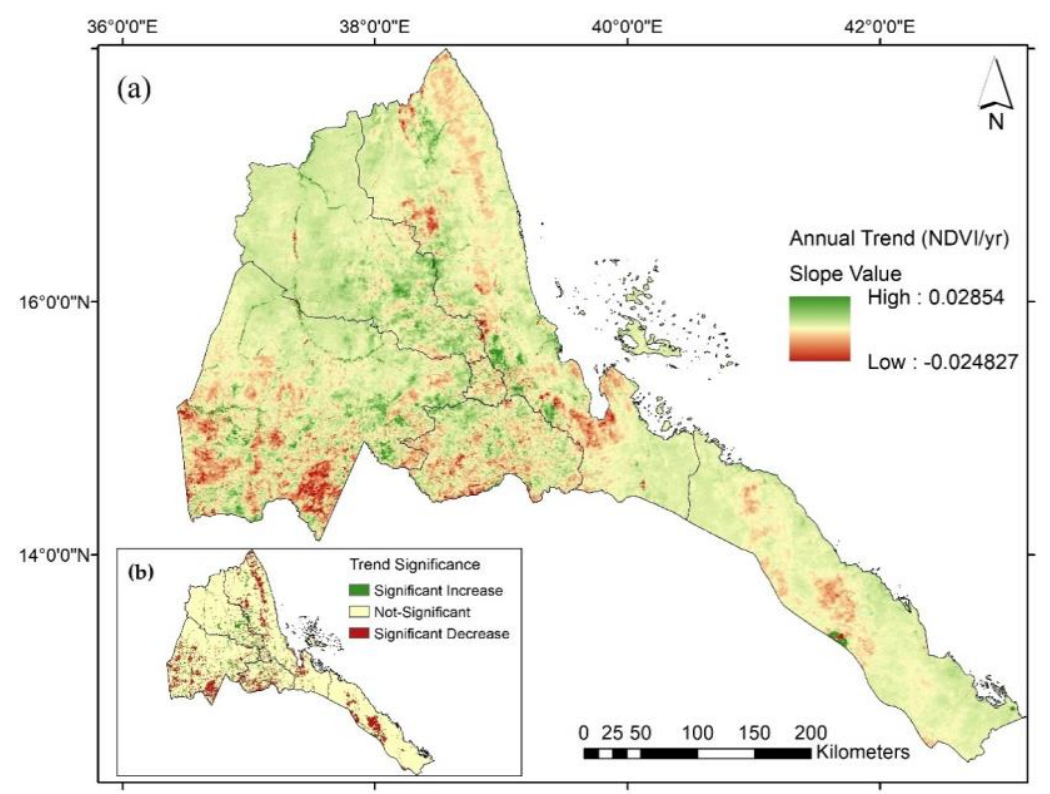

Figure 5. Cont. 


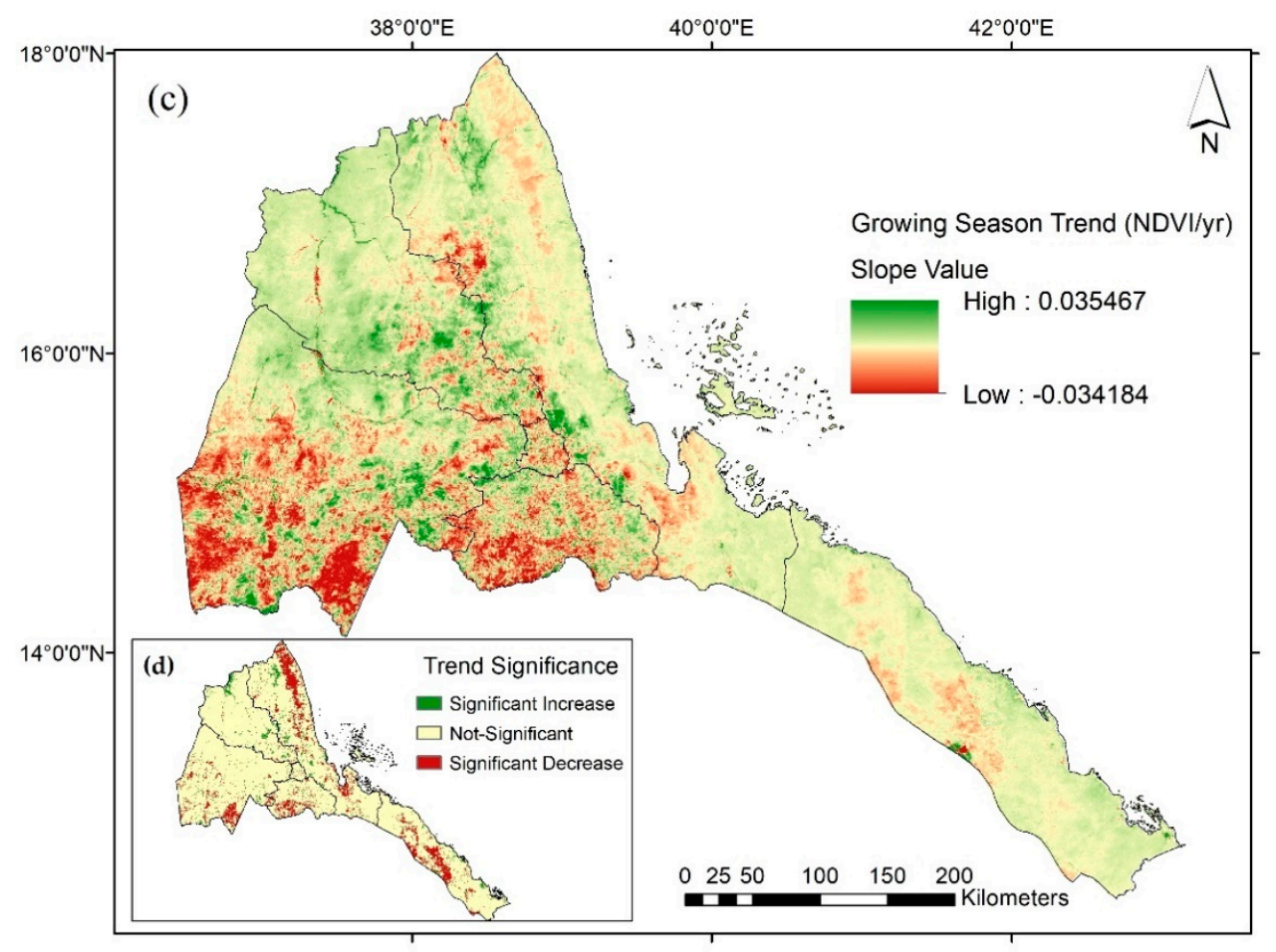

Figure 5. Normalized Difference Vegetation Index (NDVI) trends and their significance at annual and growing season time scales during 2000-2017. (a,b) Annual NDVI trend and its significance; (c,d) main growing season NDVI trend and its significance.

\subsection{Time-Series Correlation Between NDVI and Climatic Factors}

PCC was computed in order to generalize and summarize the spatial relationship and effect of the major climatic factors, such as mean total precipitation and mean temperature with MODIS vegetation indices for the annual and main growing season months. As can be observed in Figure 4, there was a decreasing pattern in mean values of the annual NDVI and EVI when compared visually with precipitation from the central highland towards Eastern and Western lowlands of the country, and there were much higher values in the South-Western parts and Eastern Escarpment. However, NDVI and EVI values were reversely correlated with temperature.

A pair-wise PCC matrix in Figure 6 represents the correlations among the major climatic variables and MODIS vegetation indices. In the linear relationship between mean annual total precipitation and mean value vegetation indices, there was a strong positive correlation between NDVI and precipitation, with an average PCC value of 0.84 at each pixel, and the same correlation was also observed between EVI and precipitation. In the linear relationship between annual mean temperature and NDVI, there was a weak negative correlation with a PCC value of -0.44 (see the orientation of the plots). The same was also true between mean annual EVI and temperature with a PCC value of -0.4036 . 


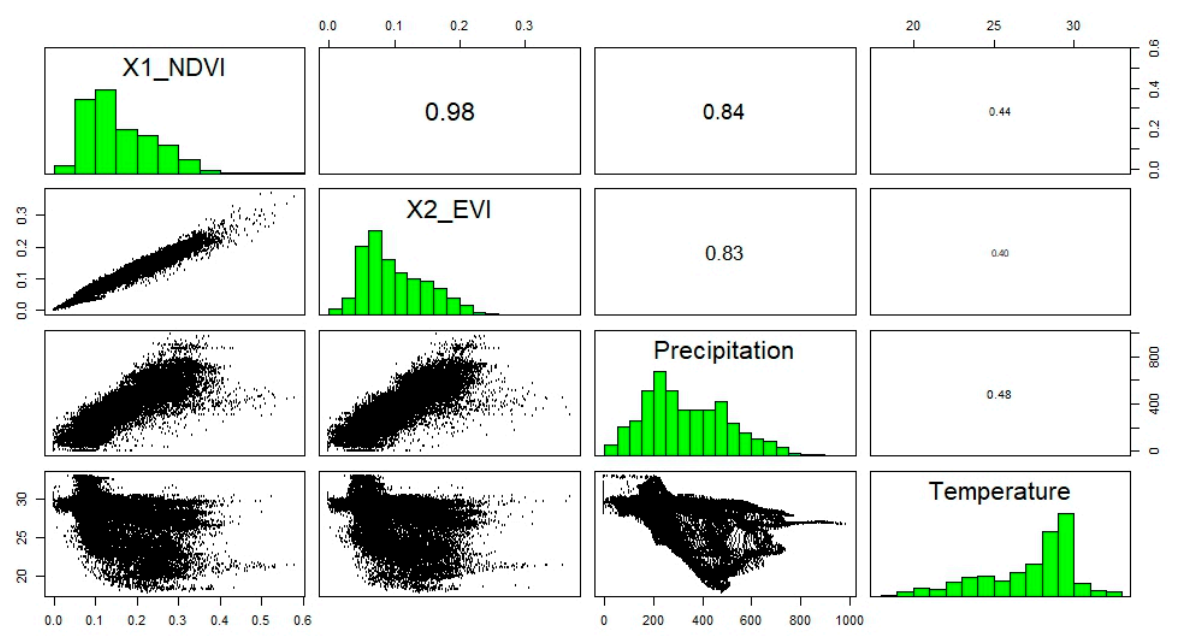

Figure 6. Pair-wise Pearson Correlation Coefficient (PCC) of mean annual NDVI (X1), EVI (X2), temperature, and average annual total precipitation during 2000-2017. The numbers represent average PCC values, and strong and weak correlations donated by large and small font sizes, respectively.

Spatial and temporal patterns of vegetation dynamics in relation to climate factors are best investigated and correlated at the pixel level of extractions [25,31]. In this study, a pixel-based correlation between NDVI and climatic factors were computed and mapped from 2000 to 2017. Figure 7 shows the results of pixel-based PCC over 18 years for annual mean NDVI versus annual total precipitation and mean temperature, along with the correlation significance outputs. The result showed that there was a positive correlation between NDVI and total precipitation in $76.95 \%$ of the entire study area (28.96\% was significant). However, $68.46 \%$ of the study area was negatively correlated with mean annual temperature (20.31\% was significant). Based on Zonal statistics extractions, using the administrative regions of Eritrea (Figure 2a), Gash Barka region followed by Debub region showed the strongest positive and most significant correlations between annual mean NDVI and annual total precipitation. On the other hand, the Northern and Southern Red Sea regions resulted in the strongest negative correlations and the highest significant correlations between annual mean NDVI and temperature. 

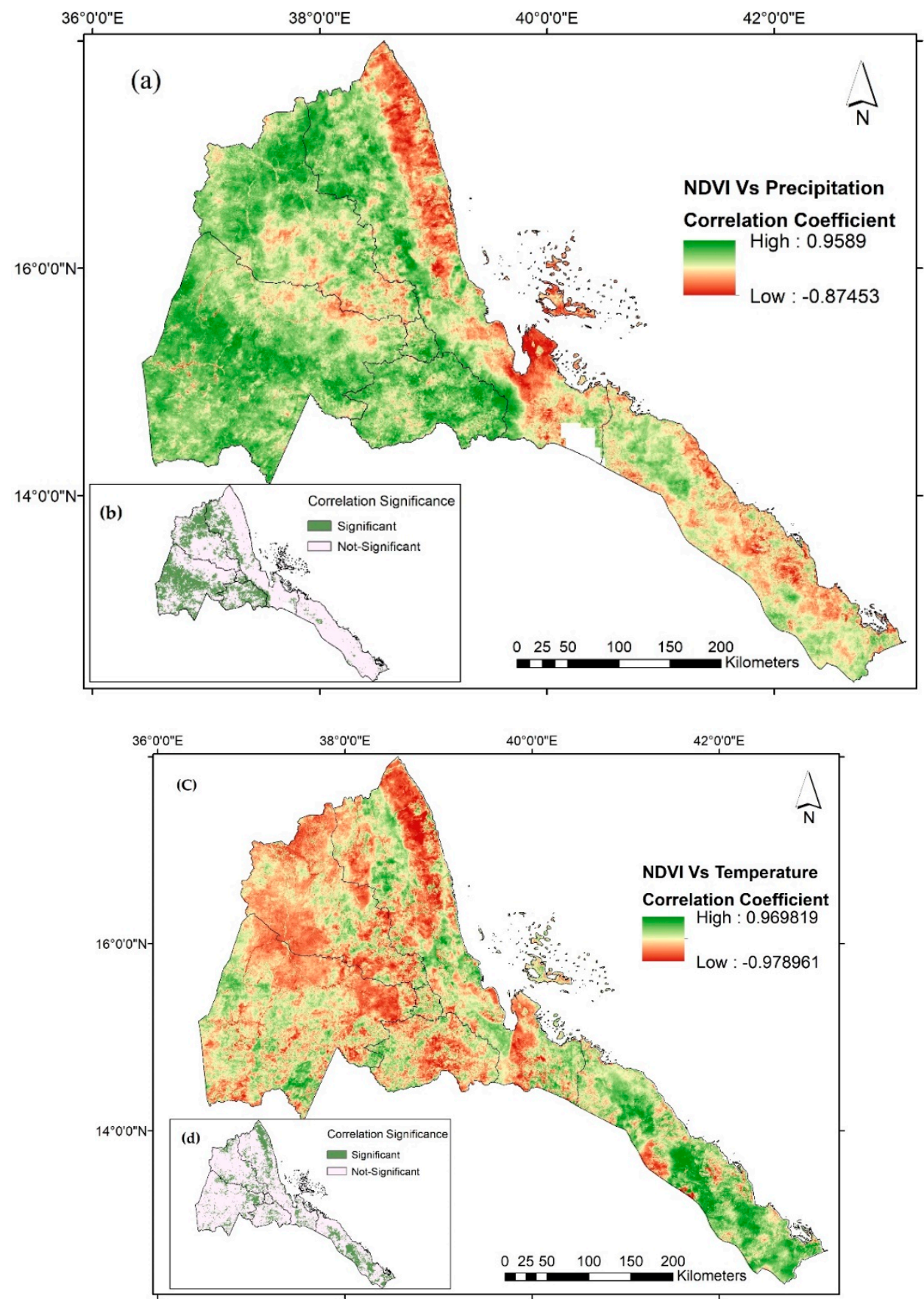

Figure 7. Correlation coefficient between annual mean NDVI versus average total precipitation (a) and mean annual temperature (c) during 2000-2017 in Eritrea; respective correlation significances (b,d).

Figure 8 shows the PCC maps extracted for the main growing season months between mean NDVI and climatic factors during 2000-2017 along correlation significance results. The growing season mean NDVI in comparison to the average total precipitation had a much stronger positive correlation than in the mean annual values; moreover, it also had a higher negative correlation with mean annual temperature. The percentage of pixels where the growing season NDVI and average total precipitation showed a positive correlation was $87.16 \%$ (39.34\% was significant), but $70.1 \%$ was negatively correlated with mean temperature (20.22\% was significant). The Gash Barka region showed the strongest positive and the most significant correlations between the growing season NDVI and precipitation. On the other 
side, the Anseba and Northern Red Sea regions were characterized by strong negative correlations, with some significant correlations between the growing season NDVI and temperature.
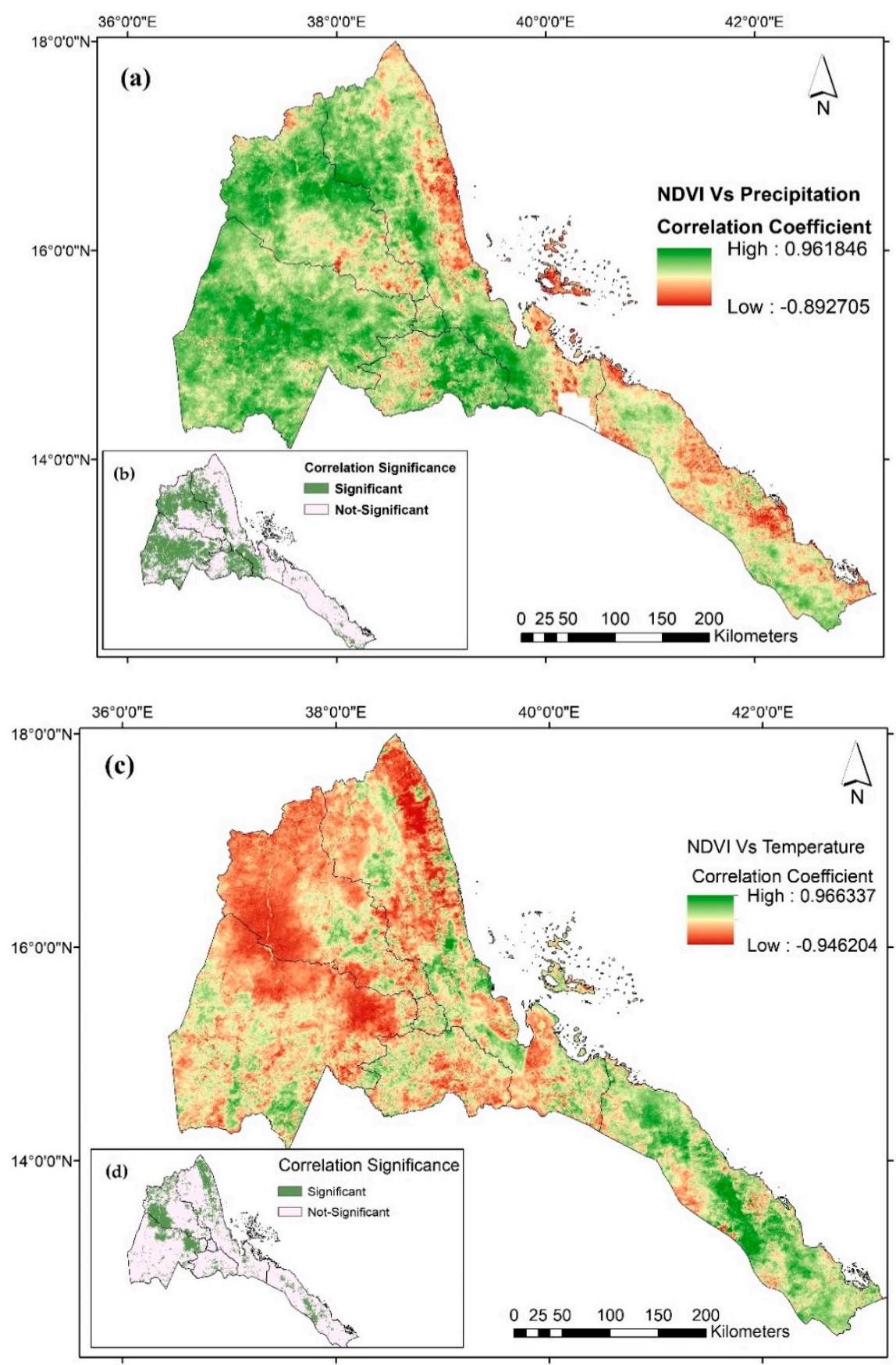

Figure 8. The correlation relationship between the growing season mean values of NDVI and the growing season total precipitation (a) and mean temperature (b) during 2000-2017, respectively; correlation significant levels are shown in $(\mathbf{b})$ and $(\mathbf{d})$.

\subsection{Spatial and Temporal Drought Patterns Based on VCI and SPI}

\subsubsection{VCI and Drought Patterns}

VCI maps were extracted based on the main growing season and multi-year minimum and maximum NDVI values calculated for every pixel of the main growing season from 2000 to 2017. VCI was used to assess drought categories of different levels for the growing season, as shown in Table 1 . 
More focus was given to the areas where vegetation condition was deteriorating, and then relevant drought events were mapped over time. This was linked back to the event of recurrent droughts in the region [17]. Figure 9 shows the temporal and spatial distributions of pixel-based mean VCI over the main growing season, which could demonstrate the agricultural drought patterns in the country.

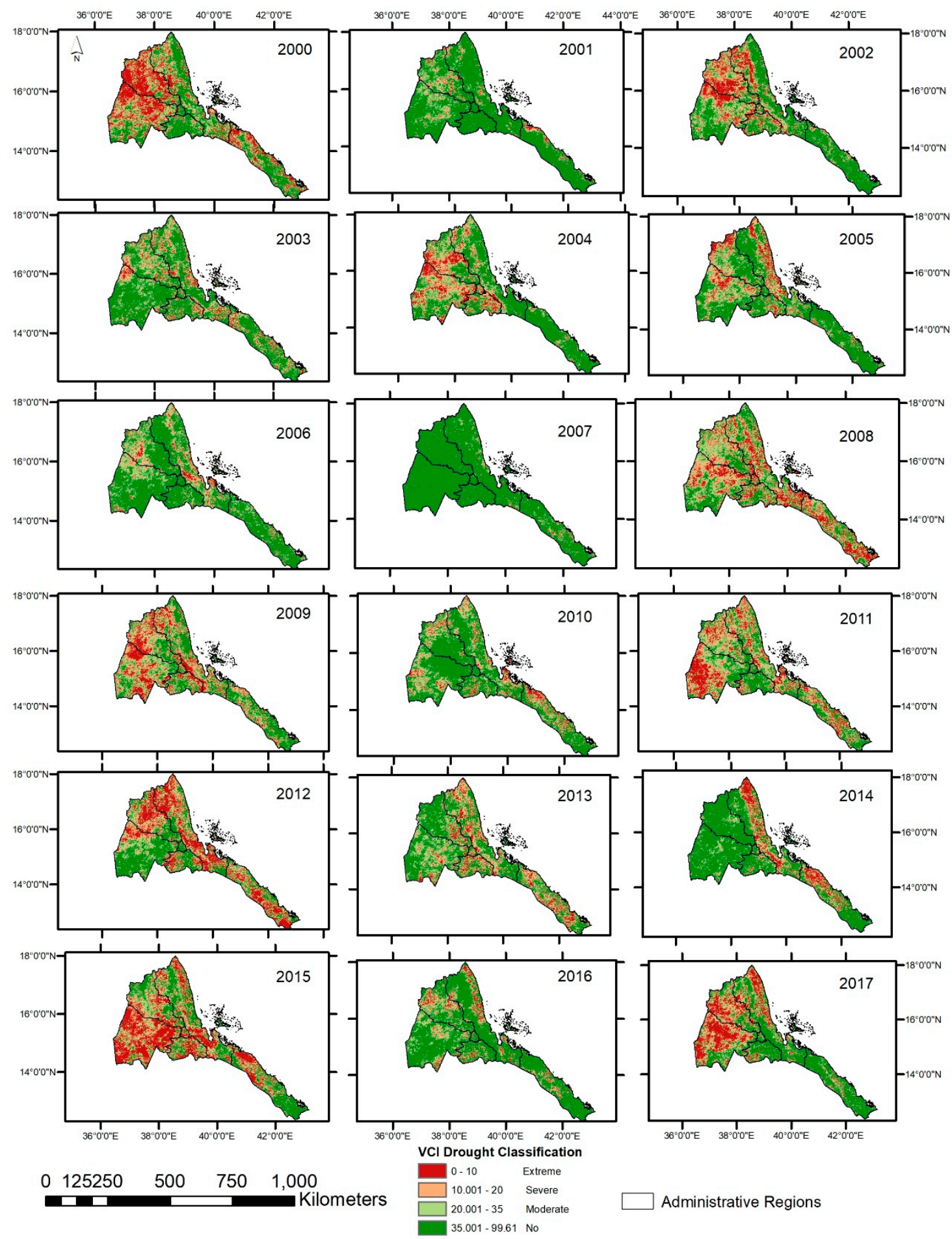

Figure 9. Pixel-based mean VCI distributions in Eritrea during 2000-2017.

As is depicted in the VCI maps of Figure 9, the years characterized by extensive drought were the years of 2000, 2008, 2009, 2011, 2012, and 2015 in the growing season period with mean VCI of less than $35 \%$. Zonal statistics analysis of all the administrative regions (Figure 2) reveals that regions which 
experienced extreme recurrent droughts throughout the observation period include the Northern Red Sea, Anseba, and Southern Red Sea. Specifically, the south-west parts of Anseba region and south-east portion of Northern Red Sea region were most vulnerable to recurrent drought, with mean VCI values less than $10 \%$.

Figure 10 shows the mean VCI classes of drought classifications during the main growing season of 2017. Areas of extreme agricultural drought were highly distributed in Gash Barka, Anseba, and Northern Red Sea regions, with mean VCI values of 21.71, 24.82 and 39.62, respectively. Integration of the results with the ESA Landcover dataset revealed sparse vegetation, grassland, and cropland covers with mean VCI values of $30.28,32.24$, and 33.76, respectively, were highly exposed from moderate to extreme levels of drought conditions.

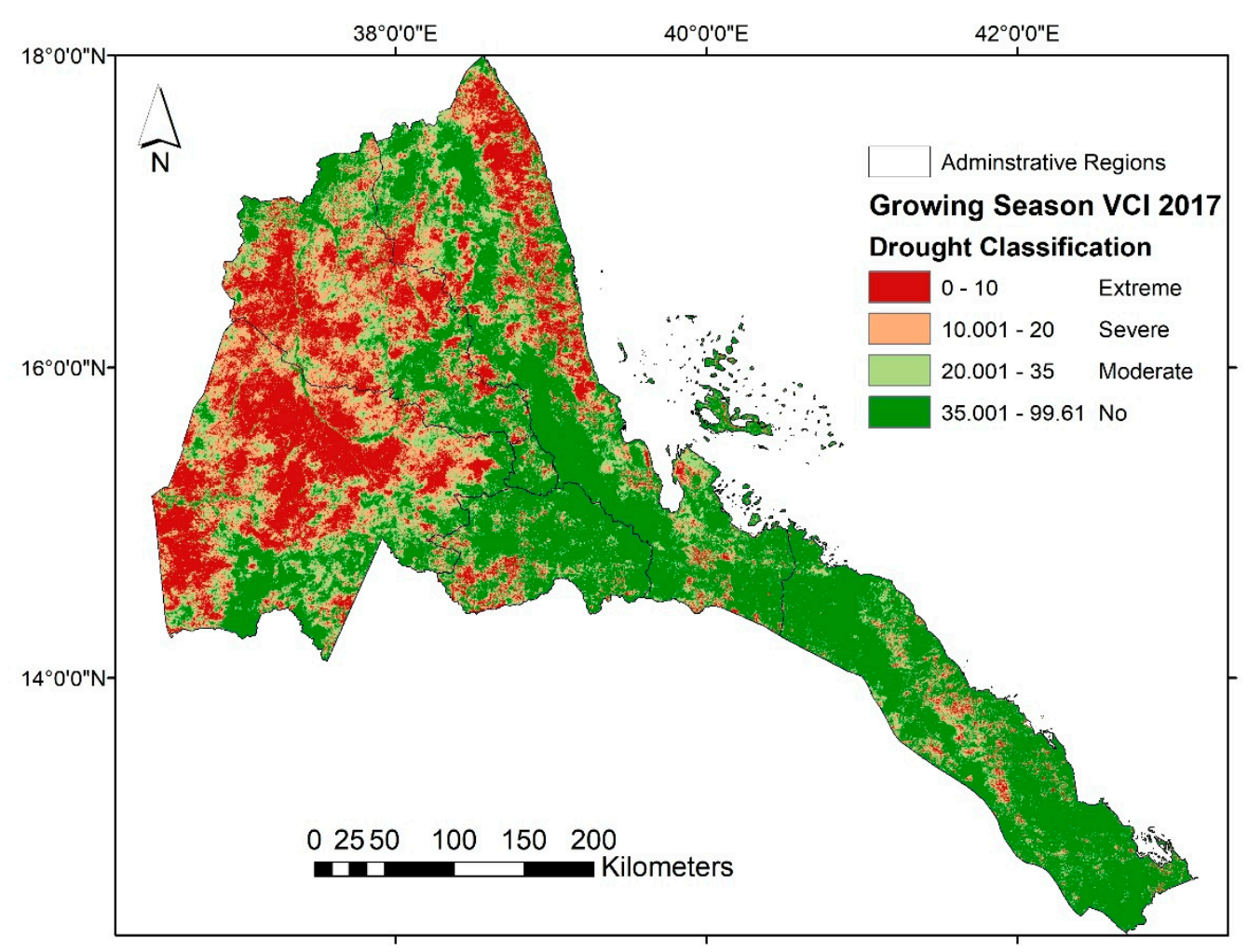

Figure 10. Mean Vegetation Condition Index (VCI ) drought classification for the main growing season of 2017.

\subsubsection{SPI and Drought Patterns}

SPI is helpful in depicting the meteorological drought patterns spatially and temporally. In Eritrea, almost $80 \%$ of the population practice rain-fed agriculture, which depends on the long rains during the main growing season. Four months of average SPI of the growing season were aggregated at pixel level, and all SPI values less than 0 were extracted to depict the drought patterns in each year of the observation period.

Figure 11 shows the four-month aggregated SPI results. The years characterized by mild to moderate drought with mean SPI values of less than 0.5 were the years of 2004, 2011, 2013, 2014, and 2015. However, values from the summary statistics show that 2002, 2008, 2011, and 2013 had a median value of less than -1 , thus moderate to extreme growing season drought conditions were dominant characteristics of these years. The most extreme median values of SPI-4 were observed in the year 2004 and 2014; the highest 1st quartile range was identified in the year 2004 and 2017, and 2015 was recorded as the highest 3rd quartile range of SPI-4. 


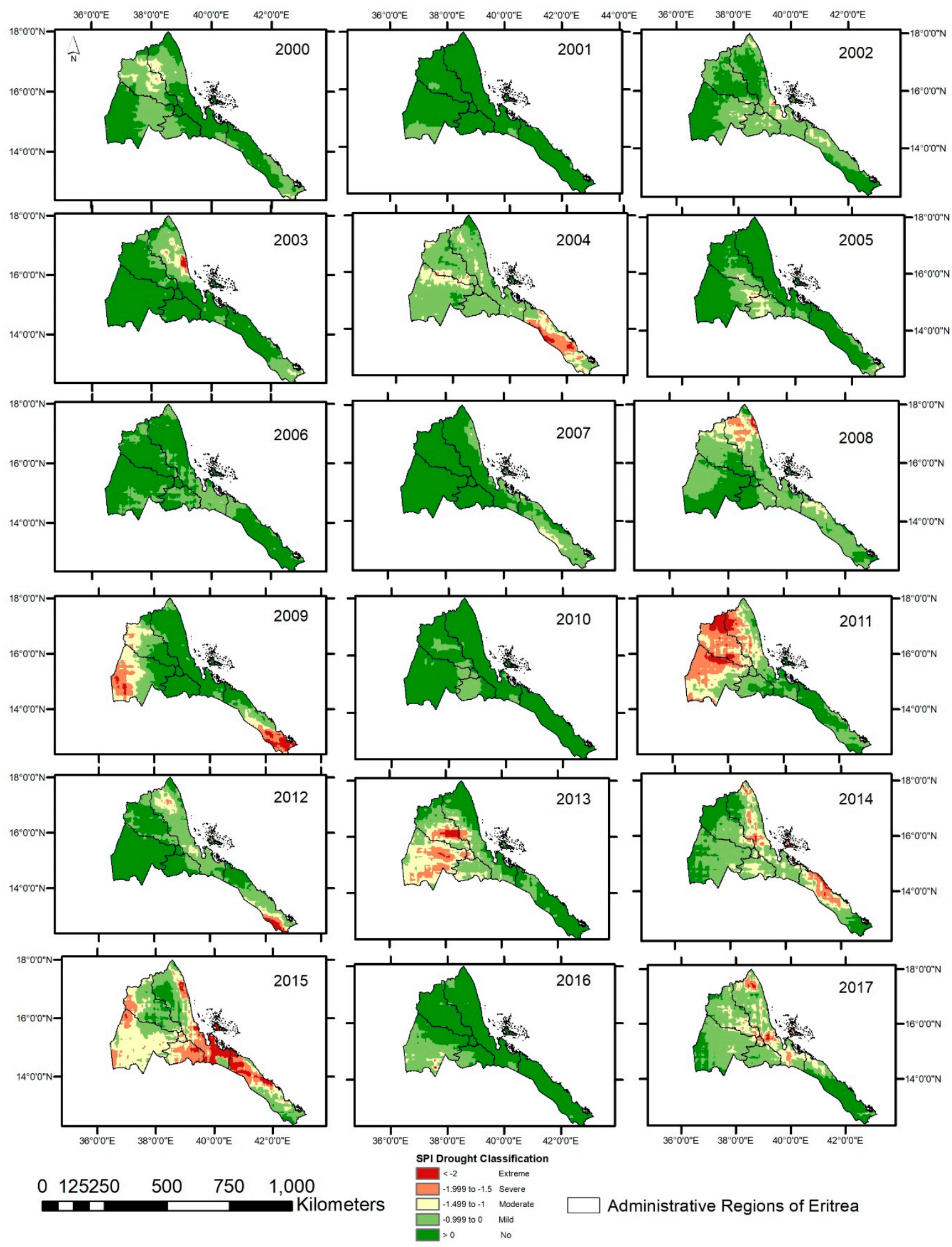

Figure 11. Aggregated SPI-4 drought conditions in Eritrea during 2000-2017.

The zonal statistics report and visual analysis of the SPI-4 month-based drought signals show that areas such as Southern Red Sea Region, Gash Barka area, and the Northern part of the Southern Red Sea Region were more prone to drought, mainly in the 2004, 2009, 2011, and 2015 growing season years, with mean SPI- 4 values ranging between -2 and -3 . The intensity of the drought was more severe from 2009 onwards, as the difference can be easily observed in the time series images (Figure 11). 
Figure 12 shows the drought classification based on SPI-4 extractions in the main growing season of 2017. Areas of extreme meteorological drought were mainly concentrated in the Northern Red Sea and Meakel regions, and some parts of Anseba region, with mean SPI-4 values of $-0.95,-1.26$, and -0.7 respectively. Merging the results with the ESA Landcover dataset shows that built-up areas, sparse vegetation, grassland, and cropland covers with mean SPI- 4 values of $-0.82,-0.77,-0.67$, and -0.61 , respectively, were exposed to different levels of drought conditions in descending order.

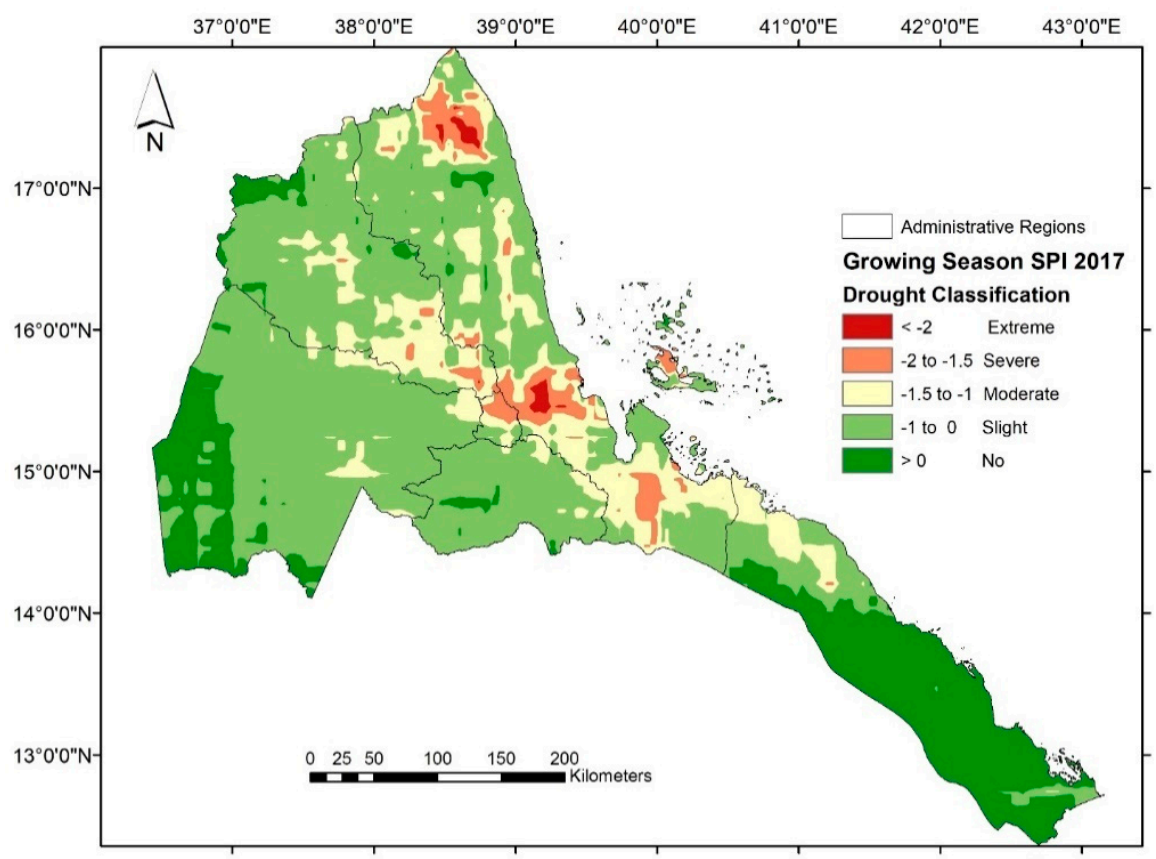

Figure 12. SPI-4 drought classification for the main growing season of 2017.

\section{Discussion}

We analyzed the trend of the vegetation dynamics over the last 18 years in Eritrea. We found that the overall pattern showed a decreasing NDVI trend, and variation through the years was considerable. Pixel-based percentage of change in the NDVI slope indicated that more than $57 \%$ of the study area showed a decreasing NDVI trend through time at both annual and main season periods, with significant changes (Figure 5). The short-term fluctuations in the NDVI values from time to time can be an important indicator for the drivers of the change. The significant negative annual NDVI trends (Figure 5a), especially in the South-Western part of the country, can be associated with the impact of agricultural drought conditions in vegetation cover and crops (Figure 8), as the shrubs and croplands are the most affected land cover types, with decreasing mean NDVI trend values. This finding matches the result of Jamali et al. [41], which is a long term study of annual NDVI of Global Inventory Modeling and Mapping Studies (GMMIS NDVI), and showed a decreasing trend for Eritrea as one of the sites in Africa. A specific study based on climate change scenarios for 2012 confirmed that a large part of the south-western area was under potential loss of yield in rain-fed sorghum due to climate change [42]. A recent study by Tesfaye [43] in Ethiopia, with similar agro-ecological characteristics as in Eritrea, also identified a general decline in NDVI trend and an effect of net-loss in greenness.

Most of the agro-ecological zones of Eritrea, except for the Sub Humid zone, showed decreasing mean NDVI trend values. The Moist Lowland and Semi-Desert zones showed the highest decrease in NDVI trends (Figures $1 \mathrm{~b}$ and $5 \mathrm{~b}$ ); this could be mainly due to the increasing aridity or recurrent droughts as the response to climate variables and deforestation activities. The Sub Humid agro-ecological zone located in the Eastern Escarpment showed an increasing mean NDVI trend, evidently because the escarpment has been protected as a national park since 2006. In the park, 
reforestation programs are commonly practiced. In addition to rains between June and September, the escarpment receives precipitation as light rains and fog deposit in November and December [44,45].

Precipitation dictates the vegetation dynamics of Eritrea. Growth and regeneration of vegetation in most parts of the country largely depend on the amount of rainfall received every year, which is reflected in the PCC and significance outputs of the main growing season (Figure 8a,b). The positive significant correlations between precipitation and NDVI, and by implication with the VCI, indicate vegetation productivity changes and drought impacts in the region; this can be helpful for agricultural drought monitoring [32]. The results correspond with the findings of Iyob [46], which stated that change in vegetation values in Eritrea can be explained mostly by precipitation. Furthermore, Ghebrezgabher et al. [40] concluded that the main factors for increased deforestation and desertification in Eritrea are rainfall variability and drought.

The strong negative correlations between the growing season mean temperatures and NDVI values (Figure $8 \mathrm{c}$ ) show that slight fluctuation in temperature might affect the decline and growth of plants. This is a great concern with the increasing temperature of the country. MoLWE states that temperature has risen by about $1.7^{\circ} \mathrm{C}$ in the past 60 years in Eritrea, with a large impact on biodiversity loss and overall loss of resilience of the ecosystem [17]. Moreover, Abera et al. [47] identified that seasonality of daytime land surface temperature was negatively correlated to vegetation greenness patterns across ecoregions in the Horn of Africa.

The agricultural and meteorological drought patterns throughout the study periods were correlated temporally and spatially with the VCI and SPI-4 outputs (Figures 9 and 11); this indicates that the meteorological drought signals were followed by agricultural drought occurrences for most of the years and places. The findings of the years 2000 and 2004 matched well with the meteorological drought analysis from the High-Resolution Spot Image and records of the National Food Information System (NFIS) of the Ministry of Agriculture of Eritrea. The NFIS report for the year 2004 stated that the main season was characterized by below normal precipitation over the 24 selected stations, while 16 stations' rainfall was lower than the long-term average, at between 100 to $306 \mathrm{~mm}$ [48].

Gholinejad, Farajollahi, and Pouzeshshow [49] and Winkler [33] revealed that there were observations of severe drought signals, and satellite extractions by Ghebrezgabher et al. [50] also confirmed that drought was very severe in 2004 and 2009. The main driver of the drought was poor rainfall during the main season, in which 2015 can be associated with El Niño (El Niño Southern Oscillation) because drought was of concern in large parts of East Africa [33]. Moreover, the analysis of the VCI during 2009 and 2015 matches with an agriculturally-relevant drought registered in the International EM-DAT (Emergency Events Database). The year 2009 was recorded as a typical drought year in Eritrea by EM-DAT, which is in line with the outputs of our VCI and SPI-4 analysis.

The outputs of both VCI and SPI-4 on the ESA land cover dataset showed that the sparsely vegetated areas, grassland, and cropland areas were highly vulnerable to drought conditions. Thus, several indigenous tree species are endangered in their habitats and rain-fed agriculture may be threatened by crop failure and production fluctuations. Farmers in Eritrea are typically dependent on grasslands for grazing livestock, and hence droughts on grasslands can be devastating. Poor rainfall areas such as Gash Barka, Northern Red Sea, and Anseba regions were the most vulnerable regions to both meteorological and agricultural drought conditions; moreover, rainfall is becoming erratic and below average because of climate variability [51]. Sea-surface effects due to adjacency to the Red Sea, and an overall increase in temperature and albedo, desertification, and deforestation have all contributed to the effect of the drought on crop production and anomalies in vegetation greenness $[40,47,52]$. Thus, there is a further need to understand and characterize dynamics of the vegetation and land cover changes in relation to drought patterns to build a base for local drought predictions in association with climate models and downscaled multi-model projections [53]. 


\section{Conclusions}

In this study, precipitation was found to be the main driving factor which determined the decreasing vegetation greenness dynamics in Eritrea, as about $76.95 \%$ of the entire study area (28.96\% significant) showed a positive correlation between mean annual NDVI and total precipitation. The correlation was much higher between the growing season NDVI and precipitation, where there was a positive correlation in $87.16 \%$ of the study area (39.34\% significant). Spatial variability and fluctuations in rainfall contributed to an overall limited vegetative cover, and there was the appearance of moderate to extreme drought conditions in sparsely vegetated grassland and cropland areas. The overall decreasing NDVI trends and vegetation greenness, especially in the southwestern part of the country, correspond to increasing aridity and recurrent drought patterns, mainly due to poor rains and rising seasonal temperatures. Impacts of the droughts and climate variability could be evidenced from shifts in agro-ecological zones and changes in the land cover, and these can cause poverty in the country. This implies that immediate action is needed to minimize such impacts in vegetation and ecosystem services, such as through integrated watershed management and climate-smart agriculture, afforestation and proper monitoring activities, complying with international environment-related conventions, and using spatial-temporal information and maintaining a sustainable environment.

Author Contributions: Conceptualization, S.M., B.C. and P.P.; Data curation, S.M.; Formal analysis, S.M., B.C., Y.T. and L.G.; Funding acquisition, B.C.; Investigation, S.M. and Y.T.; Methodology, S.M. and B.C.; Project administration, B.C.; Resources, B.C.; Software, S.M., P.P. and L.G.; Supervision, B.C.; Validation, B.C., Y.T., P.P., L.G., S.A., V.T., W.O. and T.Y.; Visualization, S.M.; Writing-original draft, S.M. and P.P.; Writing-review \& editing, B.C., Y.T., S.A., V.T., W.O. and T.Y.

Funding: The funding for this research work was provided by the Strategic Priority Research Program of Chinese Academy of Sciences (Grant No. XDA 20030302), research grant (O88RA901YA) funded by the State Key Laboratory of Resources and Environment Information System, research grants from the National Key R\&D Program of China (2017YFA0604301, 2017YFA0604302, 2018YFA0606001, and 2017YFC0503904), research grant (41771114) funded by the National Natural Science Foundation of China, and Chinese Government Scholarship in collaboration with University of Chinese Academy of Sciences.

Acknowledgments: Authors thank the Climate Hazards Group (CHG) and Climate Forecast System Reanalysis (CFSR) for making CHIRPS precipitation products and Multi-annual and seasonal mean temperature spatial datasets available through Climate Engine powered by Google Earth Engine, we also acknowledge the Moderate Resolution Imaging Spectroradiometer of the NASA for providing time series NDVI and EVI images and the European Space Agency for the land cover dataset. This work was supported by Joint Center in Earth System Science between College of Global Change and Earth System Science of the Beijing Normal University and Department of Geosciences and Geography of the University of Helsinki.

Conflicts of Interest: The authors declare no conflict of interest.

\section{References}

1. Sykes, M.T. Climate Change Impacts: Vegetation. Encycl. Life Sci. 2009. [CrossRef]

2. Na-U-Dom, T.; Mo, X.; García, M. Assessing the Climatic Effects on Vegetation Dynamics in the Mekong River Basin. Environments 2017, 4, 17. [CrossRef]

3. Niang, I.; Ruppel, O.C.; Abdrabo, M.A.; Essel, A.; Lennard, C.; Padgham, J.; Africa, P.U. Climate Change 2014: Impacts, Adaptation, and Vulnerability; Dube, P., Leary, N., Eds.; Cambridge University Press: Cambridge, UK; New York, NY, USA, 2014; Volume 22, pp. 1199-1265.

4. Bao, G.; Qin, Z.; Bao, Y.; Zhou, Y.; Li, W.; Sanjjav, A. NDVI-based long-term vegetation dynamics and its response to climatic change in the Mongolian plateau. Remote Sens. 2014, 6, 8337-8358. [CrossRef]

5. Anderson, L.O.; Malhi, Y.; Arag o, L.E.O.C.; Ladle, R.; Arai, E.; Barbier, N.; Phillips, O. Remote sensing detection of droughts in Amazonian forest canopies. New Phytol. 2010, 187, 733-750. [CrossRef] [PubMed]

6. Xie, B.; Jia, X.; Qin, Z.; Shen, J.; Chang, Q. Vegetation dynamics and climate change on the Loess Plateau, China: 1982-2011. Reg. Environ. Chang. 2015, 16, 1583-1594. [CrossRef]

7. Xie, Y.; Sha, Z.; Yu, M. Remote sensing imagery in vegetation mapping: A review. J. Plant Ecol. 2008, 1, 9-23. [CrossRef]

8. Zhong, L.; Ma, Y.; Salama, M.S.; Su, Z. Assessment of vegetation dynamics and their response to variations in precipitation and temperature in the Tibetan Plateau. Clim. Chang. 2010, 103, 519-535. [CrossRef] 
9. Fang, X.; Zhu, Q.; Chen, H.; Ma, Z.; Wang, W.; Song, X.; Zhao, P.; Peng, C. Analysis of vegetation dynamics and climatic variability impacts on greenness across Canada using remotely sensed data from 2000 to 2009. J. Appl. Remote Sens. 2014, 8, 083666. [CrossRef]

10. Thenkabail, P.S.; Gamage, M.S.D.N.; Smakhtin, V.U. The Use of Remote-Sensing Data for Drought Assessment and Monitoring in Southwest Asia; Research Report 85; International Water Management Institute: Colombo, Sri Lanka, 2004; ISBN 9290905751.

11. Suryabhagavan, K.V. GIS-based climate variability and drought characterization in Ethiopia over three decades. Weather Clim. Extremes 2017, 15, 11-23. [CrossRef]

12. AghaKouchak, A.; Farahmand, A.; Melton, F.S.; Teixeira, J.; Anderson, M.C.; Wardlow, B.D.; Hain, C.R. Remote sensing of drought: Progress, challenges and opportunities. Rev. Geophys. 2015, 53, 452-480. [CrossRef]

13. Quiring, S.M.; Ganesh, S. Evaluating the utility of the Vegetation Condition Index (VCI) for monitoring meteorological drought in Texas. Agric. For. Meteorol. 2010, 150, 330-339. [CrossRef]

14. Linés, C.; Werner, M.; Bastiaanssen, W. The predictability of reported drought events and impacts in the Ebro Basin using six different remote sensing data sets. Hydrol. Earth Syst. Sci. 2017, 21, 4747-4765. [CrossRef]

15. Rosso, C.C.; Hochrainer-stigler, S.; Pflug, G.; Condori, B. Early warning and drought risk assessment for the Bolivian Altiplano agriculture using high resolution satellite imagery data. Nat. Hazards Earth Syst. Scie. Discuss. 2018, 1-23. [CrossRef]

16. Ayana, E.K.; Ceccato, P.; Fisher, J.R.B.; DeFries, R. Examining the relationship between environmental factors and conflict in pastoralist areas of East Africa. Sci. Total Environ. 2016, 557-558, 601-611. [CrossRef]

17. Ministry of Land, Water and Environment (MoLWE). Eitrea's Intended Nationally Determined Contribution (INDCs) Report; Ministry of Land, Water and Environment (MoLWE): Asmara, Eritrea, 2015.

18. Ghebrezgabher, M.G.; Yang, T.; Yang, X.; Wang, X.; Khan, M. Extracting and analyzing forest and woodland cover change in Eritrea based on landsat data using supervised classification. Egypt. J. Remote Sens. Space Sci. 2016, 19, 37-47. [CrossRef]

19. African Development Bank. Eritrea Interim Country Strategy Paper (I-CSP) 2014-2016; East Africa Regional Resource Center (EARC): Abidjan, Côte d'Ivoire, 2014.

20. EM-DAT 2015 Eritrea-Disaster \& amp; Risk Profile I PreventionWeb.net. Available online: https:/ / www. preventionweb.net/countries/eri/data/ (accessed on 26 October 2018).

21. Food and Agriculture Organization (FAO) WATER REPKORTS. AQUASTAT Survey 2005. Irrigation in Africa in Figures; Frenken, K., Ed.; FAO Land and Water Development Division, Food And Agriculture Organization of the United Nations: Rome, Italy, 2005; Volume 29, ISBN 92-5-105414-2.

22. Didan, K. MOD13Q1 V006 I LP DAAC::NASA Land Data Products and Services. Available online: https: //lpdaac.usgs.gov/node/844 (accessed on 17 September 2018).

23. Huntington, J.L.; Hegewisch, K.C.; Daudert, B.; Morton, C.G.; Abatzoglou, J.T.; McEvoy, D.J.; Erickson, T. Climate engine: Cloud computing and visualization of climate and remote sensing data for advanced natural resource monitoring and process understanding. Bull. Am. Meteorol. Soc. 2017, 98, 2397-2409. [CrossRef]

24. Funk, C.; Peterson, P.; Landsfeld, M.; Pedreros, D.; Verdin, J.; Shukla, S.; Husak, G.; Rowland, J.; Harrison, L.; Hoell, A.; et al. The climate hazards infrared precipitation with stations-A new environmental record for monitoring extremes. Sci. Data 2015, 2, 1-21. [CrossRef] [PubMed]

25. Kang, C.H.; Zhang, Y.; Wang, Z.; Liu, L.; Zhang, H.; Jo, Y. The driving force analysis of NDVI dynamics in the trans-boundary Tumen River Basin between 2000 and 2015. Sustainbility 2017, 9, 2350. [CrossRef]

26. Jiang, L.; Jiapaer, G.; Bao, A.; Guo, H.; Ndayisaba, F. Vegetation dynamics and responses to climate change and human activities in Central Asia. Sci. Total Environ. 2017, 599-600, 967-980. [CrossRef]

27. Baniya, B.; Tang, Q. Spatial and Temporal Variation of NDVI in Response to Climate Change and the Implication for Carbon Dynamics in Nepal. Forests 2018, 9, 329. [CrossRef]

28. Weatherhead, E.C.; Reinsel, G.C.; Tiao, G.C.; Meng, X.-L.; Choi, D.; Cheang, W.-K.; Keller, T.; DeLuisi, J.; Wuebbles, D.J.; Kerr, J.B.; et al. Factors affecting the detections of trends: Statistical considerations and applications to environmental data. J. Geophys. Res. Atmos. 1998, 103, 17149-17161. [CrossRef]

29. Eckert, S.; Hüsler, F.; Liniger, H.; Hodel, E. Trend analysis of MODIS NDVI time series for detecting land degradation and regeneration in Mongolia. J. Arid Environ. 2015, 113, 16-28. [CrossRef]

30. Sun, J.; Qin, X. Precipitation and temperature regulate the seasonal changes of NDVI across the Tibetan Plateau. Environ. Earth Sci. 2016, 75, 1-9. [CrossRef] 
31. Guo, W.; Ni, X.; Jing, D.; Li, S. Spatial-temporal patterns of vegetation dynamics and their relationships to climate variations in Qinghai Lake Basin using MODIS time-series data. J. Geogr. Sci. 2014, 24, 1009-1021. [CrossRef]

32. Graw, V.; Ghazaryan, G.; Dall, K.; Gómez, A.D.; Abdel-Hamid, A.; Jordaan, A.; Piroska, R.; Post, J.; Szarzynski, J.; Walz, Y.; et al. Drought dynamics and vegetation productivity in different land management systems of Eastern Cape, South Africa-A remote sensing perspective. Sustainbility 2017, 9, 1728. [CrossRef]

33. Winkler, K.; Gessner, U.; Hochschild, V. Identifying droughts affecting agriculture in Africa based on remote sensing time series between 2000-2016: Rainfall anomalies and vegetation condition in the context of ENSO. Remote Sens. 2017, 9, 831. [CrossRef]

34. Kogan, F.; Spivak, L.; Gitelson, A.; Zakarin, E.; Lebed, L. AVHRR-Based Spectral Vegetation Index for Quantitative Assessment of Vegetation State and Productivity: Calibration and Validation AVHRR-Based Spectral Vegetation Index for Quantitative Assessment of Vegetation State and Productivity: Calibration and Va. Photogramm. Eng. Remote Sens. 2003, 69, 899-906. [CrossRef]

35. Klisch, A.; Atzberger, C. Operational drought monitoring in Kenya using MODIS NDVI time series. Remote Sens. 2016, 8, 267. [CrossRef]

36. Mckee, T.B.; Doesken, N.J.; Kleist, J. The relationship of drought frequency and duration to time scales. In Proceedings of the 8th Conference on Applied Climatology; American Meteorological Society: Boston, MA, USA, 1993; pp. 17-22.

37. Ren, G.; Zhou, Y.; Chu, Z.; Zhou, J.; Zhang, A.; Guo, J.; Liu, X. Standardized Precipitation Index User Guide. J. Clim. 2008, 21, 1333-1348. [CrossRef]

38. Pellikka, P.; Alshaikh, A.Y. Remote sensing of the decrease of juniper woodlands in the mountains of Southwestern Saudi Arabia-Reasons and consequences. Arab. J. Geosci. 2016, 9, 457. [CrossRef]

39. Soysal, Ö.M.; Schneider, H.; Shrestha, A.; Guempel, C.D.; Li, P. Zonal Statistics to Identify Hot-Regions of Traffic Accidents. In Proceedings of the 9th International Conference on Modeling, Simulation and Visualization Methods (MSV'12), Las Vegas, NV, USA, 16-19 July 2012. WORLDCOMP'12.

40. Ghebrezgabher, M.G.; Yang, T.; Yang, X. Remote Sensing and GIS Analysis of Deforestation and Desertification in Central Highland and Eastern Region of Eritrea (1972-2014). Int. J. Sci. Basic Appl. Res. 2014, 18, 161-176.

41. Jamali, S.; Seaquist, J.; Eklundh, L.; Ardö, J. Comparing parametric and non-parametric approaches for estimating trends in multi-year NDVI. In 1st EARSeL Workshop on Temporal Analysis of Satellite Images; Department of Physical Geography and Ecosystem Science: Mykonos, Greece, 2012; p. 6.

42. Waithaka, M.; Nelson, G.C.; Thomas, T.S.; Kyotalimye, M. East African Agriculture and Climate Change: A Comprehensive Analysis; International Food Policy Research Institute: Washington, DC, USA, 2013; ISBN 9780896292055.

43. Tesfaye, G.A. Monitoring Trends of Greenness and LULC (Land Use/Land Cover) Change in Addis Ababa and Its Surrounding Using MODIS Time-Series and LANDSAT Data. Master's Thesis, Department of Physical Geography and Ecosystem Science, Lund University, Lund, Sweden, 2017.

44. Fessehaye, M.; Abdul-Wahab, S.A.; Savage, M.J.; Kohler, T.; Gherezghiher, T.; Hurni, H. Assessment of fog-water collection on the eastern escarpment of Eritrea. Water Int. 2017, 42, 1022-1036. [CrossRef]

45. Eman, E.A. Eritrea Forest Genetic Resources Working Papers State of Forest Genetic Resources in Eritrea. Sub-Regional Workshop FAO/IPGRI/ICRAF on the Conservation, Management, Sustainable Utilization and Enhancement of Forest Genetic Resources in Sahelian and North-Sudanian Africa, Ouagadougou, Burkina Faso, 22-24 September 1998.

46. Iyob, B. Mapping Vegetation Using Landsat TM and ETM+ in Eritrea. Master's Thesis, Department of Geosciences, Oregon State University, Corvallis, OR, USA, 2005.

47. Abera, T.A.; Heiskanen, J.; Pellikka, P.; Maeda, E.E. Rainfall-vegetation interaction regulates temperature anomalies during extreme dry events in the Horn of Africa. Glob. Planet. Chang. 2018, 167, 35-45. [CrossRef]

48. National Food Information System (NFIS) of Eritrea, Ministry of Agriculture. Monthly Food Security Outlook, Kremti Season Special Edition; National Food Information System (NFIS) of Eritrea, Ministry of Agriculture: Asmara, Eritrea, 2004.

49. Gholinejad, B.; Farajollahi, A.; Pouzesh, H. Environmental factors affecting on distribution of plant communities in semi- arid area (Case study: Kamyaran rangelands, Iran). Ann. Biol. Res. 2012, 3, 3990-3993. 
50. Ghebrezgabher, M.G.; Yang, T.; Yang, X. Long-term trend of climate change and drought assessment in the Horn of Africa. Adv. Meteorol. 2016, 2016, 8057641. [CrossRef]

51. Environment and Energy of United Nations Development Programme (UNDP), Case Study of Eritrea. Climate Change Adaptation Project Report in Water and Agriculture in Anseba Region, Keren, Eritrea, 2012; Environment and Energy of United Nations Development Programme: New York, NY, USA, 2012.

52. Heiskanen, J.; Rautiainen, M.; Maeda, E.E.; Abera, T.A.; Pellikka, P. Clarifying the role of radiative mechanisms in the spatio-temporal changes of land surface temperature across the Horn of Africa. Remote Sens. Environ. 2018, 221, 210-224. [CrossRef]

53. Hwan, M.; Eun, L.; Im, S.; Bae, D.H. A comparative assessment of climate change impacts on drought over Korea based on multiple climate projections and multiple drought indices. Clim. Dyn. 2019. [CrossRef]

2019 by the authors. Licensee MDPI, Basel, Switzerland. This article is an open access article distributed under the terms and conditions of the Creative Commons Attribution (CC BY) license (http:/ / creativecommons.org/licenses/by/4.0/). 